\title{
Colecistectomia com vesícula biliar do lado esquerdo (sinistroposição): Relato de
} caso

Cholecystectomy with left gallbladder (sinistroposition): case report Ermerson Machado Timm ${ }^{1}$, Alexandre Chartuni Pereira Teixeira ${ }^{2}$

1. Médico Residente de Cirurgia Geral no Hospital Regional de Sobradinho - DF

2. Médico Especialista em Cirurgia Geral e Cirurgia do Aparelho Digestivo; Preceptor do Programa de Residência Médica em Cirurgia Geral do Hospital Regional de Sobradinho - DF; Mestre em Gastroenterologia Cirúrgica pela Universidade Federal de São Paulo.

\section{RESUMO}

O presente caso tem como objetivo relatar um caso de Colecistectomia Videolaparoscópica de uma paciente com Colecistite Aguda associada a uma vesícula biliar em posição inabitual no Hospital Regional de Sobradinho - DF no ano de 2019. Informações obtidas através de revisão de prontuário, anamnese, fotografias intra-operatória, revisão literária.

A vesícula biliar é um órgão intraabdominal com a função de armazenar a bile produzida pelo fígado, cuja localização habitual é abaixo do lobo direito hepático lateral ao ligamento falciforme. A Colecistite consiste na inflamação da vesícula biliar, tendo como principal origem a doença calculosa da vesícula biliar. A vesícula biliar localizada medialmente ao ligamento falciforme (sinistroposição) é uma condição rara, correspondendo a cerca de $0,3 \%$ em um estudo feito com pacientes submetidos à Colecistectomia Videolaparoscópica. O diagnóstico dessa condição é feito habitualmente de forma incidental durante exames de imagem ou durante cirurgias intra- abdominais. Reconhecer essa condição trará ao cirurgião expertise para lidar com eventual adversidade. Comumente ao se deparar com essa condição o cirurgião tem que realizar uma dissecção mais ampla, realizar colangiografia intraoperatória ou até mesmo conversão para cirurgia aberta para melhor reconhecimento da anatomia.

Palavras-chave: Colecistectomia, Colecistite Aguda, Sinistroposição.
ABSTRACT
The present case aims to report a case of Videolaparoscopic Cholecystectomy of a patient with Acute Cholecystitis associated with a gallbladder in an 
unusual position at the Hospital Regional de Sobradinho - DF in 2019. Information obtained through medical record review, anamnesis, intra photographs -operative, literary review. The gallbladder is an intra-abdominal organ with the function of storing the bile produced by the liver, whose usual location is below the right hepatic lobe lateral to the sickle cell ligament. Cholecystitis consists of inflammation of the gallbladder, with the main origin being calculus gallbladder disease. The gallbladder located medially to the sickle cell ligament (sinistroposition) is a rare condition, corresponding to about $0.3 \%$ in a study conducted with patients undergoing video laparoscopic cholecystectomy. The diagnosis of this condition isusually made incidentally during imaging exams or during intra-abdominal surgeries. Recognizing this condition will bring the surgeon the expertise to deal with eventual adversity. Commonly when faced with this condition, the surgeon has to perform a broader dissection, perform intraoperative cholangiography for even conversion to open surgery for better recognition of the anatomy.

Keywords: Cholecystectomy, Acute cholecystitis, Sinistroposition

\section{INTRODUÇÃO}

A vesícula biliar é um órgão intraabdominal tendo como principal função a de armazenar a bílis produzida pelo fígado, cuja localização habitual é abaixo do lobo direito hepático lateral ao ligamento falciforme ${ }^{1,3}$. A Colecistite consiste na inflamação da vesícula biliar tendo como principal causa a colelitíase $^{1,2,5}$. A presença da Vesícula Biliar no lado esquerdo é uma condição rara e com poucos relatos na literatura atual, sendo descrita pela primeira vez por Hochstetter em 1886 com um estudo mostrando uma prevalência em cirurgias de colecistectomias Videolaparoscópica de cerca de $0,3 \% \%^{4,6}$.

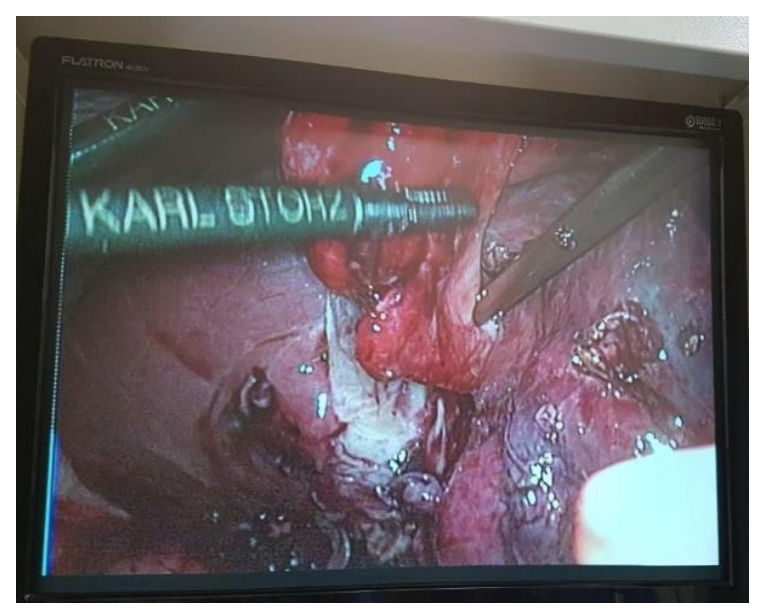

Figura 1: Evidencia a Vesícula Biliar e o ligamento falciforme. 


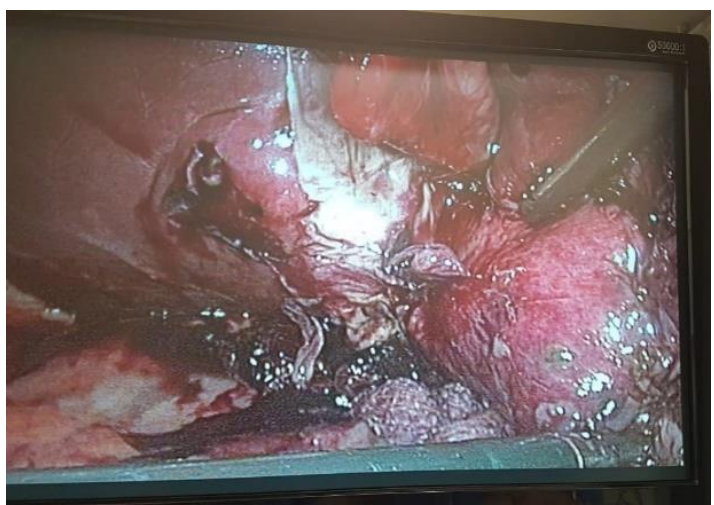

Figura 2: Dissecção da Vesícula Biliar.

\section{RELATO DE CASO}

Paciente do sexo feminino 22 anos, com dor abdominal há dois dias localizada em epigástrio e hipocôndrio direito com irradiação para dorso direito associada a náuseas e vômitos. Apresentava no exame físico inicial, sinal de Murphy positivo. Exames iniciais apresentavam elevação de leucócitos com desvio à esquerda, elevação de enzimas canaliculares e discreta elevação de bilirrubinas. Ultrassom com presença de cálculos no interior da vesícula biliar e espessamento da parede. Histórico de colelitíase identificado em exame ultrassonográfico anteriormente sem outras comorbidades. Feito o diagnóstico de Colecistite Aguda litiásica, foi indicada cirurgia em caráter de urgência e durante o inventário foi observado a presença vesicular biliar medial ao ligamento falciforme, caracterizando a sinistroposição (figura I e II).

\section{DISCUSSÃO LITERÁRIA \\ $\mathbf{E}$ \\ REVISÃO}

A vesícula biliar é um órgão intraabdominal com forma de Pera/Beringela localizada habitualmente na borda inferior do lobo hepático direito, cuja principal função é armazenar a bile $e^{7,8,9}$. A sinistroposição que corresponde a vesícula biliar no lado esquerdo, é uma condição rara, incidentalmente encontrada no intra-operatório de cirurgias de Colecistectomia por vídeo ou convencional ou durante exames de imagem $^{4}$. O conhecimento dessa condição por parte do cirurgião, se tratando de uma condição rara, trará ao cirurgião mais expertise para lidar com eventual situação, principalmente para evitar lesões iatrogênicas das vias biliares, uma das complicações mais temidas pelos cirurgiões e mais prevalente nesse tipo de cirurgia ${ }^{10}$. Essa anomalia não impede a realização da colecistectomia nem indica a conversão para cirurgia convencional em caso de cirurgia por vídeo, todavia, fortuitamente o cirurgião realiza colangiografia intraoperatória ou converte para cirurgia convencional para melhor identificação da anatomia biliar ${ }^{1}$. 
No presente relato houve dificuldade no manejo cirúrgico devido ao processo inflamatório e posição da vesicular biliar, entretanto não foi necessária a realização decolangiografia intra-operatória nem a conversão para cirurgia aberta.

\section{REFERÊNCIAS}

1. Sabiston Tratado de cirurgia / Courtney

M. Townsend, Jr. ... [et al.] - Rio de Janeiro: Elsevier, 2015.

2. Robbins, Patologia básica / Vinay Kumar... [et al]; [tradução de Claudia Coana... et al.]. - Rio de Janeiro: Elsevier, 2013. 928 p.: il.

3. Hall, John E. (John Edward), 1946Tratado de Fisiologia Médica [recurso eletrônico] / John E. Hall; [tradução Alcides Marinho Junior ... et al.]. - Rio de Janeiro: Elsevier, 2011. Recurso digital: il.

4. Dhulkotia A, et al. Aberrant gallbladder situated beneath the left lobe of liver. HPB. 2002;4(1):39-42.
5. Internal Clinical Guidelines Team (outubro de 2014). «Gallstone Disease: Diagnosis and Management of Cholelithiasis, Cholecystitis and Choledocholithiasis. Clinical Guideline 188»: 101.

6. Reddy PK, et al. Laparoscopic cholecystectomy for leftsided gallbladder (sinistroposition). JSLS. 2005; 9(3):356-7. 2. Reddy PK, Subramanian RV, Yuvaraja S. Laparoscopic cholecystectomy for leftsided gallbladder (sinistroposition). JSLS. 2005; 9 (3):356-7.

7. Rouvière, H., Anatomía Humana Descriptiva, topográfica y funcional, 11a ed. (C2005 Últ. Reimpr. 2006, Volume 2 Anatomía humana: descriptiva, topográfica y funcional, Henri Rouvière.

8. Frank H. Netter, MD: Atlas of Human Anatomy, Fifth Edition, Saunders Elsevier, Chapter 4 Abdomen, Subchapter 28 Viscera (Accessory Organs), Guide Abdomen: Viscera (Accessory Organs) - Gall Bladder.

9. Neil S. Norton, Ph.D. and Frank H. Netter, MD: Netter's Head and Neck 
Anatomy for Dentistry, 2nd Edition,

Elsevier Saunders, Chapter 22

Introduction to the Upper Limb, Back,

Thorax and Abdomen, Page 597.

10. Machado, Ricardo Rossetto. "Lesões iatrogênicas da via biliar: experiência de

21 anos de um centro de referência

terciário." (2014). 